\title{
Global Carbon Emission Trading Market and China's Sustainable Development
}

\author{
Chen Jian \\ International Business Faculty \\ Beijing Normal University, Zhuhai \\ Zhuhai, P.R.China \\ chenjian@bnuz.edu.cn
}

\author{
Li Maoguan \\ International Business Faculty \\ Beijing Normal University, Zhuhai \\ Zhuhai, P.R.China \\ 88977139@qq.com
}

\begin{abstract}
This paper starts by describing China's carbon emissions trading market development history, reveals the existence of its development problems, then, analyzes the successful establishment of the European and American national carbon emissions trading market experiences. At last, this paper recommends for a call of unified effort to improve domestic carbon emissions trading market system. An agreement with the EU will see some cooperation with the design of China's trading platforms.
\end{abstract}

Keywords-Carbon Emissions Trading Market; Kyoto Protocol; Sustainable Development;China

\section{INTRODUCTION}

The development of carbon emissions trading market will have a great impact on the development of China in the future. People's awareness of environmental protection will be gradually improved, and the development of low-carbon economy is imperative. As the world's largest emitter, China will begin her regional pilot schemes in 8 cities from 2013 onwards with a view to establishing a national market in the future.

China as a responsible developing country, actively respond to the "Kyoto Protocol" in the face of severe problems of climate warming, try to reduce greenhouse gas emissions. And in November 2011, the State Council approved the "Twelfth Five working plan for controlling greenhouse gas emissions "clearly put forward to explore and establish carbon emissions trading market to further control of greenhouse gas emissions. Under the increasing pressure to reduce emissions, China as the world's first big country of carbon emissions, impels to develop a resource-saving and environment-friendly road. In fact, carbon emissions trading market is both opportunities and challenges. The opportunities are that the low carbon economy has increasingly become a development road of various countries economic and China is committed to the development of carbon emissions trading market that is to cater to the trend of the development of the times. China early enter into this new market, which is conducive to China to get rid of "pollution first, treatment later" ,the old road of development and through technical exchanges between countries to reduce the cost of carbon emission reduction. China's resource gift of carbon emissions is superior and current carbon emissions reduction has been around the world's $1 / 3$, only next to the United States.[1] Beside, China timely access to carbon emissions trading market is conducive to better establish the relevant trading system, to standardize the relevant laws and regulations, to attract the relevant talent and to do a good job related to the supervision, which improve the entire carbon emissions trading market system. However, the challenge of building carbon emissions trading market should not be ignored. .

\section{INTERNATIONAL CARBON TRADING MARKET DEVELOPMENT FOR CHINA'S REFERENCE}

\section{A. General Situation of International Market}

Carbon emissions trading market is a new commodity market and has been rapid development after the "Kyoto protocol" in 2005. At present, the international carbon trading market is mainly conducted in the regional market, while the various financial institutions play an important role in this market. Due to the responsibility and the specific conditions of different regions, there is not yet a unified trading system in the world and all the regions are actively exploring their own carbon emissions trading patterns. According to the world bank's data report, during 2005-2011 years, the international carbon trading market turnover of account and trading volume of the average annual basic has maintained a good momentum which the total turnover respectively reached 1.08 billion, 3.12 billion, 6.4billion, 12.63billion, 14.37billion, 15.92billion and 17.6billion. Besides, the U.S. official data forecast that in 2020 the global carbon market transactions will reach \$2500 -3000 U.S. dollars and the market development gradually mature.[2]

\section{B. Successful International Carbon Trading Market Model}

Carbon trading market is seen by many as the most effective market-based system to encourage greenhouse gas emission reductions. The World Bank estimated that carbon trading worth a total of \$176bn took place during 2011. Specifically, we take China, Japan, South Korea, China Taiwan, New Zealand, Australia, India, Vietnam and Mexico for example:[3]

1. China Mainland, being the world's largest emitter will begin regional pilot schemes in seven cities from 2013 onwards with a view to establishing a national market in the future. Heavy emitting industries and electricity producers will be included at first. An agreement with the EU will see some cooperation with the design of China's trading platforms. 
2. Tokyo has launched a city-wide scheme that applies to large office buildings and industrial infrastructure, which are required to use a combination of renewable energy and efficiency measures to stay within a prescribed emissions cap.

3. South Korea is an increasingly active country in climate change diplomacy, as host of the Green Climate Fund and the Global Green Growth Institute. South Korea will also begin carbon trading in 2015. More than half the country's emissions will be covered by the scheme, which includes 500 of its heaviest emitters.

4. China Taiwan hopes to reduce emissions back to 2005 levels by 2020 and has requested that 270 of its larges emitters begin reporting their emissions ahead of the launch of a cap and trade system.

5. New Zealand trading scheme does cover a wide range of sectors including agriculture, energy, liquid transport fuels and waste, although the system includes only every second tonne of carbon emitted. It also rewards sectors such as forestry with credits for absorbing $\mathrm{CO}_{2}$ from the atmosphere.

6. Australia launched a carbon price of $\mathrm{A} \$ 23$ per tonne of $\mathrm{CO}_{2}$ emitted with 300 of the country's largest emitter included. A link-up with the EU market is scheduled for 2018.

7. India's mandatory Perform, Achieve and Trde(PAT) scheme differs slightly from the other platforms with industrial emitters given biding energy efficiency targets rather than emission allowances. Over achievers can trade the fruits of their labour with other companies.

8. Vietnam announced plans to reduce its emissions from forestry and agriculture by $20 \%$ in May 2012. A carbon trading scheme will be established to meet the goal.

9. Mexico's previous government established strong climate change legislation including a 30\% reduction in emissions by 2020. A voluntary cap and trade mechanism has been proposed however there are few details available on its design and a change in government as of December 1, 2012 could affect the plans.

Among the successful ones, there are: EU Emissions Trading Scheme(ETS) in EU, Chicago Climate Exchange, Western Climate Initiative(WCI) in the US and Canada, and Regional Greenhouse Gas Initiative (RGGI) in north east of the US, etc.

\section{1) EU Carbon Emissions Trading System}

The EU carbon emissions trading system (EU ETS) plan is divided into two stages: the first three years of the system is the first phase of the system from 2005 to 2007. This stage achieves $45 \%$ of "the Kyoto Protocol" commitment to emission reduction targets. The second phase will achieve will achieve the Kyoto Protocol, the commitment of all the emission reduction targets of the Kyoto Protocol commitment during 2008 to 2012.

The trading system is a decentralized governance model; the EU member has a great deal of autonomy on the setting of total emission, distribution and transaction registration. EU ETS adopt the "limited and trade" trading system that the EU Member States must submit to the country's total carbon emissions quota plan to the EU audit, in the total carbon emissions, the enterprises of each member should in strict accordance with the indicators after the total amount of carbon emissions. If the enterprise still has surplus total amount of carbon emissions under the premise of the total amount of carbon emissions restrictions, it can transfer their carbon trading rights in the carbon trading market. EU ETS's punishment system is that the relevant corporate will be punished by 40 Euros if its carbon dioxide emissions more than 1 tons per year. And from 2008 year the penalty upgrade to 100 Euros and the enterprise' emissions permit reduce by corresponding number in the following year.

\section{2) Chicago Climate Exchange}

Under the Kyoto Protocol, Chicago Climate Exchange (CCX), the world's first legal emissions trading platform, came into being. CCX emission reduction plan divided into two stages: The first stage (2003 -2006) all commitment member annually reduce $1 \%$ based on the baseline emission level. The second stage all commitment members make emission level down to $6 \%$ of baseline. [4]These commitments member can reduce emissions internally, buying license from other company, who has saved emission permit, or purchase credit line produced by specific quota emission reduction projects. In addition, an electronic trading platform can be developed for its members of commitment to reduce emission by making online transactions, which all not disclosed and supervised by the United States National Securities Dealers Association.

\section{CURRENT Situation OF China'S CARbON TRAding MARKET}

\section{A. Development of Carbon Trading Market in China}

The construction of carbon trading market is the new direction of the global economic development. In order to meet this challenge and opportunity, China has already actively promote the construction of domestic carbon trading platform, August 5, 2008, the Shanghai environmental and energy exchange and the Beijing Environmental Exchange was established on the same day; in September 25, 2008, Tianjin Emissions Exchange listing was set up[5]. Despite China's positive response to the trend of carbon trading market of international construction, but the domestic carbon trading volume is small. This is because the international carbon trading market downturn in 2008 and the domestic intellectuals know little about carbon trading so this result. However our country didn't give up the idea of building carbon trading market. In November 2011, the national development and Reform Commission issued "About the carbon emissions trading pilot working" that promised Tianjin City, Beijing City, Chongqing City, Guangdong Province, Hubei Province, Shenzhen city and other seven provinces and cities to carry out carbon emissions trading experimental unit which took a big 
step toward establish a unified carbon trading market system. June 18, 2013, Shenzhen carbon trading Gong opened; during November to December, Shanghai, Beijing, Guangdong, Tianjin have started carbon trading pilot work.[6]

For the actual emission limits of various experimental units of carbon emissions, China has also made the corresponding punishment mechanism. If the pilot place exceeds the agreed amount of emissions, we must accept the quota price of 3 to 5 times the fine. For example, when the quota price of 60 Yuan / ton, the fine is 300 Yuan / ton.[7]

At present, the main form of domestic carbon trading is the quota transaction. The government set the corresponding emissions for the relevant industries or enterprises and enterprises can accord their own situation to sell or purchase the emission rights. All in all, the emissions of enterprises should meet the requirements of the country. Although, compared with the western countries, China's carbon trading market has a obvious gap, China is developing countries. According to the "Kyoto Protocol", we have not been forced to fulfill the obligations of emission reduction and the western developed countries have been constrained, so their emission reduction costs higher than China's, which will attract the developed countries to actively cooperate with us to save emission reduction cost under the premise in common to achieve emission reduction targets.

Around the world, China is already the world's second largest economy so developed countries have asked China to take greater responsibility on emission reduction work. In the international appeal, how can we do both to ensure the smooth development of the domestic carbon trading market and does not affect the growth of GDP, which has become a more important issue in our country. As China is in the process of industrialization and urbanization, many industries in China are second industries. Many domestic industries' development rely on raw materials which still produce a lot of greenhouse gas, such a soil, coal; which is a big problem to complete the international requirements of China's emission reduction work.

\section{B. Problems in Development of Carbon Emissions Trading Market in China}

Carbon emissions trading market has many problem in Chinese development. In order to better integrate into the international carbon emissions trading market, we need to do enough attention. In general, I think there are six important problems in our country's carbon emissions trading market:

1) Carbon Financial System Development not Perfect, Transaction Risk Exists[8]

A sound legal protection can regulate and restrict the orderly development of carbon emissions trading, the European Union and the United States of the trading system has a strict law as the guarantee of its development. Carbon emissions have a distinct characteristic of financial products and carbon index trading involves bank loans, Options and Future, etc. The subjects of carbon emissions trading abroad mainly deal by investment banks and other financial institutions and these institutions minutely understand the carbon trading. Due to fact that our country development of carbon trading market in is late, domestic enterprises is not clear about the value of carbon finance, the operation mode while the financial market is not perfect. There is a huge security risk in such a platform under the transaction.

\section{2) Gas Emission Right Initial Distribution Unfair}

This situation is mainly due to two reasons: firstly, enterprises unwilling to premature undertaken many emission reduction work, therefore in the provisions of the total carbon emissions in the form of lease to borrow carbon emissions from other relevant enterprises, which leading to a more powerful enterprises can guarantee accord quantity to complete the emission reduction work, meanwhile some small businesses just shell companies which just matching carbon emissions for large companies. So market regulatory role is not apparent. Secondly, the regulation of carbon emissions trading is regulated by the relevant departments of the country for managing the total carbon emissions, which may cause carbon emissions trading under the control of the relevant departments.

3) China's Cleaner Production Technology Restricted the Development

Because our country's cleaner production technology than the European and American countries have a more obvious gap. Because our country "s cleaner production technology has the obvious gap, compared to the European and American countries. Therefore, the higher cost of our country's production product make the price of carbon emissions right deviate the real price of the product and influence the market mechanism fully play the function. Clean production technology has a great impact on the efficiency and fairness of carbon emissions trading mechanism.

\section{4) Carbon Emissions Trading Policy Planning not Appropriate}

Carrying out carbon emissions trading involves many aspects, such as total amount, clearing and settlement system, market supervision system and so on, but our country has no unified regulations, policy disorders, which lead to the development of carbon trading market, cannot be smooth and fast, which seriously affect the implementation of carbon emissions trading.

\section{5) Carbon Emission Pricing Mechanism Missing}

Price can reflect the value of the product; the real price can effectively promote the rational development of the market. In China, the value of the product is generally measured in accordance with the foreign pricing mechanism which ignores to establish our own pricing mechanism. In addition, due to the country's initial emissions share, under the interests of the government and enterprises, the price of carbon emissions trading is distorted by man-made, which result in the market transaction price is not standardized?

6) Government's Supervision on Trading Market not Strict Enough

At present, China's carbon emissions trading market trading mechanism is not perfect. There are still many problems in the environmental monitoring and monitoring facilities for technical development and how to establish a supervisory authority with prestige has become a guarantee for the development of carbon trading market in the future. 


\section{CHINA'S CARBOn EMISSIONS TRADING MARKET COUNTERMEASURES SUGGESTED}

This paper puts forward the following suggestions:

\section{A. Increasing Technical Input of CDM Project}

When foreign buyers of CDM project cooperate with China, most of case is that the funds instead of technical output. A large part of the reason is worried about their production technology has been stolen, even if the introduce production technology; the technology has been eliminated in foreign country. Therefore, improving the protection of domestic intellectual property rights ensure that foreign countries provide more technical assistance to China, so China's enterprises can improve production efficiency and increase economic benefits. However, this approach is not always the long-term plan; our country should get technical assistance and continue to develop their original production technology as far as possible to closer the foreign advanced production technology to develop belongs to the cleaner production technology of Chinese characteristics.

\section{B. Actively Change the Position of China's Carbon Trading Industry Chain}

China is the world's largest supplier of CDM carbon emission. Due to the small number of words in the international carbon emissions market, our country has been in the lowest part of carbon trading industry chain in a long-term. And Chinese CER is usually purchased by developed countries with very low price, while developed countries sell it to in second market with a high price to get huge profits, which make our government lost a lot of economic interests. Therefore, our country strive to cultivate more talents of carbon trading market, accelerate the transformation of industrial structure and improve the clean production technology, to obtain the right to speak in the international carbon trading market and rid himself of the lowest part of the carbon trading industry chain.

\section{Improving Legal System of Carbon Trading Market}

The perfect legal system is an important measure for the smooth development of the carbon trading market. However, there are no clear legal provisions on the confirmation of the legal status of carbon emissions trading, and the settlement of the problems in the process of carbon trading. Therefore, China should expedite the construction of the legal system of carbon trading market, and make detailed provisions on the formulation, distribution, transaction and punishment rules in carbon trading process. In addition, it should clearly show that how to deal with the bankrupt enterprises in carbon trading market, so that domestic enterprises have laws to go by.

\section{Strengthening Carbon Trading Market Supervision}

The intangible nature of carbon trading rights makes the supervision of the domestic relevant departments of the carbon trading market have a relatively large loss. Because of the intangible nature of carbon trading, the relevant departments are difficult to accurately identify the different stages of corporations 'carbon emissions, which affect the confirmation of the carbon volume and finally influence the normal operation of carbon trading market. In order to solve this problem, I think that the relevant departments should strictly audit the qualification of the emissions of carbon dioxide emissions market requirements and then to establish a compliance reporting system which the report includes the condition of carbon emissions, the condition of carbon trading, etc. finally, relevant departments should set up a specific regulatory system to monitor whether the enterprise in accordance with the requirements of the carbon emissions quotas and to monitor the Legal compliance of domestic carbon trading market requirements.

\section{E. Vigorously Promoting the Application of High and New Technology}

At present, when Chinese carbon emissions technology is relatively backward, we should actively learn from foreign advanced cleaner production technology and encourage enterprises to introduce advanced production technology, improve the utilization rate of fuel, which can reduce emissions and increase economic benefits. At the same time, China should actively call for industry restructuring, adjust the industrial structure and further improve China's carbon emissions trading market system, which achieve the goal of Chinese energy-saving emission reduction and sustainable development

\section{F. Establishment of the Market of Carbon Finance Mechanism}

Carbon emissions trading market is developing to the direction of the financial market, during the time, China needs to use financial markets to achieve the economic benefits of carbon industry, while China should strengthen the development of banking, securities, insurance and other financial institutions, forming a variety of carbon finance market.

\section{CONCLUSION}

With the development of the times, people's awareness of environmental protection is gradually improving, and the development of low-carbon economy is imperative. In this opportunity and challenge coexist; China should intensify its own cleaner production technology, try hard to reduce the cost of production of carbon products, which make our own get higher international discourse to get rid of the lowest position of the carbon trading market.

In the process of development, China should try to learn from foreigner successful experience, develop a set of carbon trading market theory that accord her specific condition and cultivate more talents of carbon trading, to enhance the competitiveness of the country in the international carbon trading market. An agreement with the EU will see some positive cooperation with the design of China's trading platforms. 


\section{REFERENCES}

[1] Zhen Xiaoxi. “The Development of International Carbon Emissions Trading and Its Enlightenment to China”, Sichuan Environment, vol.2, pp. 105-108, 2014.

[2] Liuyu. “Current Problems in China's Carbon Trading Pilot”. Oriental Morning Post, Beijing: Chinese People Press, 2013

[3] Carbon Market Data, [Online], Available: https://www.carbonmarketdata.com/en/home[2 April 2017].

[4] Futao, Litao. "Exploration of Carbon Emissions Trading Market". Business and Economic Management, vol.1, pp.3-5, 2010,

[5] Qian Guoqiang, Yi Liqi. “Analysis on the Current Situation and Future Trend of Carbon Trading Market. Environment and Sustainable Development”, vol.3, pp.5-18, 2012.
[6] Yao Xiaofang, "Chenqing. European and American Carbon Emissions Trading Market Development for China's Enlightenment and Reference”. Exploration of Economic Problems, vol.5, pp.1-5. 2011.

[7] Zhao Liming, Zhanghan. "Analysis on the Risk Management of Carbon Emissions Market in China”. Tianjin Environmental Protection Series, vol.6, pp.10-15, 2011.

[8] Wang Tianhui, Shunhui. "International Reference and Revelation of Carbon Finance Development in Low Carbon Economy”. Golden Card Project and method, vol.4, pp. 3-8, 2010.

[9] John Wilson."The World Bank Carbon Finance Annual Report”,Carbon Finance for Sustainable Development, pp.5-6. April, 2006. 